С. А. Гриневич, А. А. Гришкевич

Белорусский государственный технологический университет

\title{
РАСЧЕТ ЖЕСТКОСТИ ОСЕЙ КОГТЕВЫХ ЗАВЕС
}

Одним из факторов травматизма на деревообрабатывающих производствах является обратный вылет обрабатываемого материала или его элементов. Наибольший риск вылета характерен для деревообрабатывающих круглопильных станков для продольной распиловки натуральной древесины. С целью удержания заготовки или ее элементов в станке предназначены завесы из предохранительных упоров (когтевые завесы).

Основные требования к конструкции когтевых завес приведены в технических нормативных правовых актах. Одним из условий эффективной работы завесы из предохранительных упоров является прочность и жесткость ее элементов, и прежде всего оси, на которой подвижно установлены предохранительные упоры. И если с точки зрения прочности нормативные документы определяют требования к ее материалу, то с точки зрения жесткости таких требований нет. В то же время деформация оси при восприятии ударной нагрузки может быть значительной. Это подтверждается опытом анализа конструкций круглопильного оборудования, на котором имели место несчастные случаи, связанные с обратным выбросом заготовок. Предохранительные упоры на таких станках зачастую проворачивались в обратную относительно направления подачи сторону, а ось когтевых завес имела существенную пластическую деформацию.

В работе приведены и проанализированы требования технических нормативно-правовых актов, предьявляемые к параметрам осей когтевых завес. На основании рекомендуемых параметров геометрии оси и требований к ее прочности выполнены расчеты стрелы прогиба в зависимости от разных способов ее фиксации. Проведенные исследования выявили проблемы при использовании рекомендаций нормативных актов.

Ключевые слова: когтевая завеса, ось, прочность, жесткость, деформация.

Для цитирования: Гриневич С. А., Гришкевич А. А. Расчет жесткости осей когтевых завес // Труды БГТУ. Сер. 1, Лесное хоз-во, природопользование и перераб. возобновляемых ресурсов. 2021. № 2 (246). C. 345-349.

\section{S. A. Grinevich, A. A. Grishkevich \\ Belarusian State Technological University \\ STIFFNESS CALCULATION OF THE CLAW CURTAINS AXES}

One of the factors of injuries in woodworking industries is the reverse ejection of the processed material or its elements. The greatest risk of the ejection is typical for woodworking circular sawing machines for longitudinal sawing of natural wood. To hold the workpiece or its elements in the machine curtains of safety stops (claw curtains) are designed.

The main requirements for the design of a claw curtain are given in the technical regulations. One of the conditions for the effective operation of curtains of safety stops is the strength and rigidity of its elements and, above all, the axis on which the safety stops are movably set. And if from the point of view of strength, regulatory documents define the requirements for its material, then from the point of view of rigidity, there are no such requirements. At the same time, the deformation of the axis during the impact load can be significant. This is confirmed by the experience of analyze the designs of circular sawing equipment, where accidents associated with the reverse ejection of material have occurred. The safety stops on such machines were often turned in the opposite direction from the feed direction, and the axis of the claw curtains had a significant plastic deformation.

In the paper the requirements of technical regulations for the parameters of the axes of the claw curtains are presented and analyzed. Based on the recommended parameters of the axis geometry and the requirements for its strength, the deflection depending on the different ways of fixing it is calculated. The conducted research revealed problems when using the recommendations of regulatory acts.

Key words: claw curtain, axis, strength, rigidity, deformation.

For citation: Grinevich S. A., Grishkevich A. A. Stiffness calculation of the claw curtains axes. Processing of BSTU, issue 1, Forestry. Nature Management. Proceedings of Renewable Resources, 2021, no. 2 (246), pp. 345-349 (In Russian). 
Введение. Вопросы повышения безопасности эксплуатации промышленного оборудования не теряют своей первостепенной важности. В том числе это относится и к деревообрабатывающей промышленности, где уровень травматизма продолжает оставаться довольно высоким. Основными причинами несчастных случаев при эксплуатации деревообрабатывающего оборудования являются соприкосновение оператора с подвижными частями станка и режущим инструментом, а также обратный выброс обрабатываемого материала или его элементов. Последнее наиболее характерно для круглопильных станков, осуществляющих продольную распиловку древесины $[1,2]$.

При этом, согласно Закону «Об охране труда» [3], наниматель обязан обеспечить безопасные условия труда. А согласно Правилам [4], деревообрабатывающее оборудование должно иметь защитные устройства, исключающие в процессе работы выбрасывание режущим инструментом обрабатываемых заготовок и отходов. Требования безопасности к деревообрабатывающему оборудованию регламентируются ТР ТС 010/2011 «О безопасности машин и оборудования» [5]. Для удержания заготовки в станке при ее обратном выбросе предназначены завесы из противовыбрасывающих упоров, установленных, как правило, в несколько рядов (когтевые завесы). Основные требования к конструкции данного типа устройств изложены в ГОСТ 12.2.026.0-93 «Станки деревообрабатывающие. Требования безопасности к конструкции» [6] и СТБ ЕН 1870-4-2006 «Безопасность деревообрабатывающих станков.
Станки круглопильные. Часть 4. Станки многополотные для продольной резки с ручной загрузкой и/или выгрузкой» [7]. Также некоторые вопросы работоспособности когтевых завес были рассмотрены в работе [8].

Основная часть. При рассмотрении конструкций завес из противовыбрасывающих упоров на круглопильных станках, бывших в эксплуатации, а особенно на тех из них, где имели место несчастные случаи, связанные с обратным выбросом распиливаемого материала, была отмечена деформация осей когтевых завес. Очевидно, что сила от удара вылетающей заготовки была велика на столько, что произошла упругая деформация металлического стержня. С одной стороны, это подтверждает высокую скорость выброса элементов обрабатываемого материала [9], а с другой - о недоработках в конструкции механизма противовыбрасывающих упоров.

Минимальный диаметр оси противовыбрасывающих упоров определяется по графику (рис. 1) согласно СТБ ЕН 1870-4-2006 [7].

При этом вышеуказанный нормативный документ предлагает только одну расчетную схему (рис. 2).

К материалу оси приводится только одно требование - сталь с минимальным пределом прочности на растяжение $\sigma_{\mathrm{p}}=570 \mathrm{H} / \mathrm{MM}^{2}$ [7]. Соответственно, допускаемое напряжение при изгибе $\sigma_{\text {изг }}$ МПа, может быть найдено как [10]

$$
\left[\sigma_{\text {изг }}\right]=\frac{\sigma_{\mathrm{p}}}{n},
$$

где $n$ - коэффициент запаса.

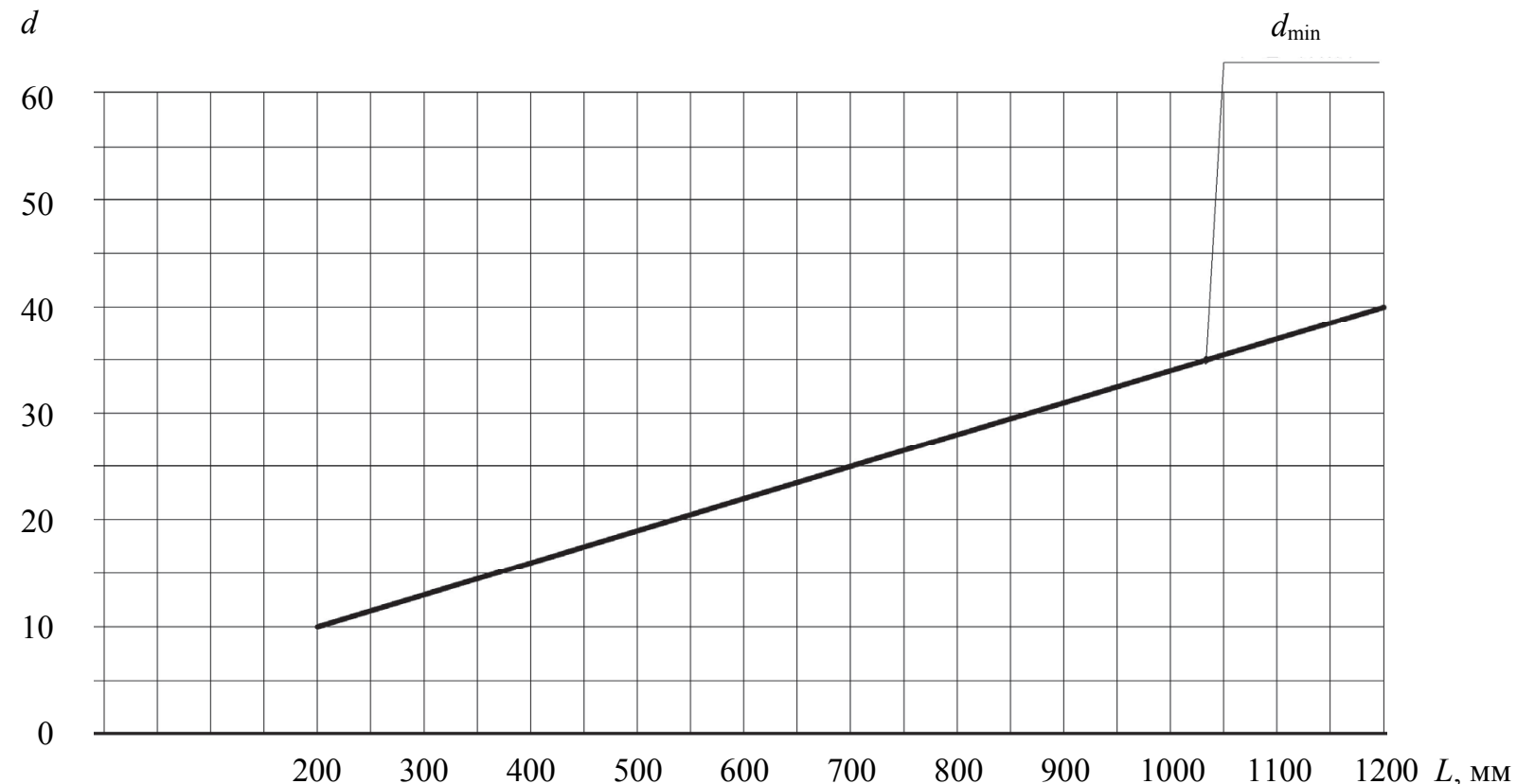

Рис. 1. График для определения минимального диаметра оси когтевой завесы 
Коэффициент запаса варьируется в довольно широких пределах - от 1,3 до 5,0 [10]. Выбор значения $n$ осуществляется с учетом конкретных условий работы конструкции и, по сути, должен назначаться на основе опыта создания аналогичных конструкций. Рекомендаций по его выбору вышеуказанный нормативный документ не приводит.

Однако прочность - не единственный критерий расчета диаметра оси механизма. Ее жесткость должна также играть роль, так как значительная деформация оси может создать условия для вылета элементов обрабатываемого материала, особенно малой толщины.

При этом следует отметить разнообразие конструкторских решений при монтаже оси в опорах, и не все из них сводятся к схеме, представленной на рис. 2.

$L$

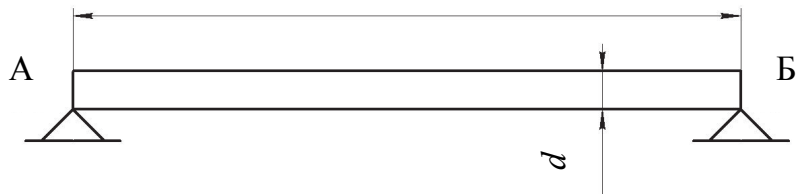

Рис. 2. Схема к определению минимального диаметра оси когтевой завесы

Так, на рис. 3 представлен вариант установки оси в опорах и осевой фиксацией за счет стопорных колец.

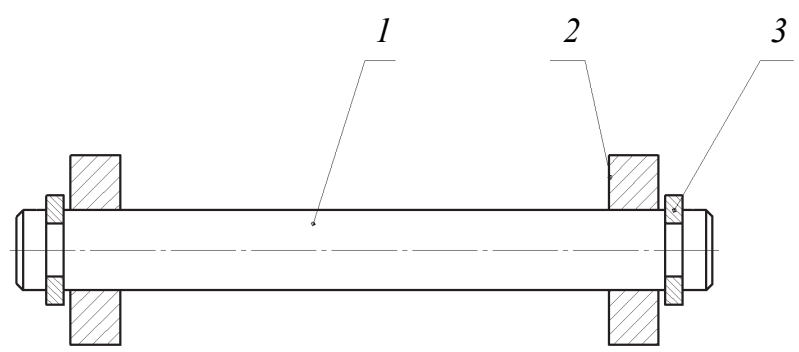

Рис. 3. Установка оси со стопорными кольцами

На рис. 4 представлена конструкция с установкой оси в опорах и ее последующей фиксацией штифтами.

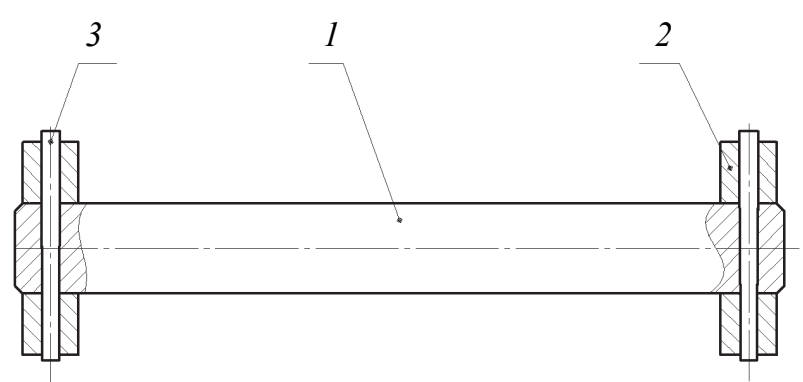

Рис. 4. Установка оси со штифтами
Очевидно, что вариант конструкции, показанный на рис. 3, может быть приведен к схеме, представленной на рис. 2.

Определим максимальный изгибающий момент $M_{\text {изг }}, \mathrm{H} \cdot \mathrm{M}$, из условия прочности [11]:

$$
M_{\text {изг }}=\left[\sigma_{\text {изг }}\right] \cdot W,
$$

где $W$ - момент сопротивления сечения, мм ${ }^{3}$.

Так как ось имеет круглое сечение, то

$$
W=\frac{\pi \cdot d^{3}}{32} .
$$

Значение нагрузки $F, \mathrm{H}$, приложенной по середине балки, для создания заданной величины изгибающего момента [8]

$$
F=\frac{4 \cdot M_{\text {изг }} .}{l} .
$$

С учетом (1)-(4) можем записать

$$
F=\frac{\pi \cdot d^{3} \cdot \sigma_{\mathrm{p}}}{8 \cdot n \cdot l} .
$$

Величина стрелы прогиба для рассматриваемой схемы может быть определена как [9]

$$
y=\frac{F \cdot l^{3}}{48 \cdot E \cdot J},
$$

где $E$ - модуль Юнга, Н/мм² $; J$ - момент инерции сечения, мм ${ }^{4}$.

Для круглого сечения $J, \mathrm{mM}^{4}$, найдем по формуле [10]

$$
J=\frac{\pi \cdot d^{4}}{64} .
$$

Перепишем (6) с учетом (5) и (7):

$$
y=\frac{\sigma_{\mathrm{p}} \cdot l^{2}}{6 \cdot E \cdot d \cdot n} .
$$

Пользуясь данными графика (рис. 1), определим для примера силу и стрелу прогиба, полагая $E=2 \cdot 10^{5} \mathrm{H} / \mathrm{MM}^{2}, n=2, l=700 \mathrm{мм}$, $d=25 \mathrm{Mm}$.

$$
\begin{gathered}
F=\frac{3,14 \cdot 25^{3} \cdot 570}{8 \cdot 2 \cdot 700}=2497 \mathrm{H} ; \\
y=\frac{570 \cdot 700^{2}}{6 \cdot 2 \cdot 10^{5} \cdot 25 \cdot 2}=4,655 \mathrm{MM} .
\end{gathered}
$$

Для варианта со штифтами расчетной схемой будет являться балка с защемленными концами (рис. 5). 


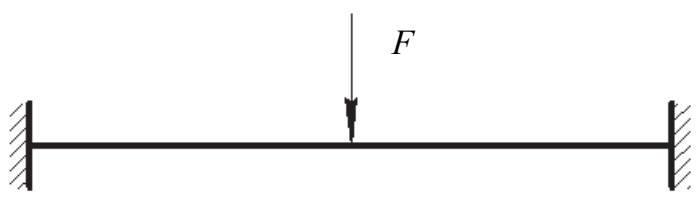

Рис. 5. Расчетная схема при установке оси со штифтами

Для этой схемы значение нагрузки $F, \mathrm{H}$, приложенной по середине балки, для создания заданной величины изгибающего момента [11]

$$
F=\frac{8 \cdot M_{\text {изг }}}{l} .
$$

Соответственно,

$$
F=\frac{\pi \cdot d^{3} \cdot \sigma_{\mathrm{p}}}{4 \cdot n \cdot l} .
$$

Величина стрелы прогиба для рассматриваемой схемы может быть определена как [12]

$$
y=\frac{F \cdot l^{3}}{192 \cdot E \cdot J} .
$$

Аналогично перепишем формулу для определения стрелы прогиба с учетом (7) и (10):

$$
y=\frac{\sigma_{\mathrm{p}} \cdot l^{2}}{12 \cdot E \cdot d \cdot n} .
$$

Рассчитаем силу и стрелу прогиба для аналогичных условий:

$$
F=\frac{3,14 \cdot 25^{3} \cdot 570}{4 \cdot 2 \cdot 700}=4994 \mathrm{H}
$$

$$
y=\frac{570 \cdot 700^{2}}{12 \cdot 2 \cdot 10^{5} \cdot 25 \cdot 2}=2,328 \mathrm{MM} .
$$

Сопоставляя полученные результаты при расчетах для схем, указанных на рис. 2 и 5, видим, что схема с заделанными концами оси когтевых завес выдерживает в 2 раза большую нагрузку до достижения предела прочности и обеспечивает в 2 раза более высокую жесткость.

Заключение. Существующие рекомендации, приведенные в отечественных ТНПА, не совершенны, так как не учитывают всех факторов, влияющих на эффективность работы когтевых завес, а именно:

1) не учтены конструктивные особенности крепления осей когтевых завес. Как показал расчет, правильный выбор крепления может не только повысить прочность и жесткость конструкции, но и позволяет снизить ее металлоемкость;

2) графическая зависимость (рис. 1), предложенная в СТБ ЕН 1870-4-2006 по выбору диаметра оси когтевой завесы, вызывает вопросы, так как согласно формулам сопротивления материалов, соотношения $l$ и $d$ не носят линейный характер ни с точки зрения прочности, ни с точки зрения жесткости;

3) отсутствуют рекомендации по выбору коэффициента запаса, и нет даже ориентировочных значений нагрузок, воспринимаемых когтевыми завесами.

На основании вышеизложенного очевидно, что необходимы дополнительные экспериментальные и теоретические исследования, направленные на определение сил, возникающих при срабатывании когтевых завес и совершенствование конструкций последних.

\section{Список литературы}

1. Гришкевич А. А., Гриневич С. А., Гаранин В. Н. К вопросу об обеспечении безопасности при эксплуатации круглопильного оборудования: материалы докл. 84-й науч.-техн. конф., посвященной 90-летнему юбилею БГТУ и Дню белорусской науки (с международным участием), Минск, 2020. Минск: БГТУ, 2020. С. 152-153.

2. Волкович Д. С. Определение угла заклинивания зубчатой завесы: тез. докл. 71-й науч.-техн. конф. учащихся, студентов и магистрантов БГТУ. Минск: БГТУ, 2020. С. 229-231.

3. Об охране труда: Закон Респ. Беларусь от 23 июня 2008 г. № 356-3: в ред. от 18 дек. 2019 г. № 274-3. URL: https://pravo.by/upload/docs/op/H1 1900274_1577394000.pdf (дата обращения: 20.03.2021).

4. Правила по охране труда при ведении лесного хозяйства, обработке древесины и производстве изделий из дерева: постановление Министерства труда и соц. защиты Респ. Беларусь и Министерства лесного хозяйства Респ. Беларусь № 32/5 от 30.03.2020. URL: https://pravo.by/upload/docs/op/W2203 5383p_159018100.pdf (дата обращения: 20.03.2021).

5. О безопасности машин и оборудования: TP TC 010/2011. URL: http://www.eurasiancommission.org/ru/act/texnreg/deptexreg/tr/Documents/P_823_1.pdf (дата обращения: 19.03.2021).

6. Оборудование деревообрабатывающее. Требования безопасности к конструкции: ГОСТ 12.2.026.0-1993. Введ. 01.01.1996. Минск: Гос. ком. по стандартизации Респ. Беларусь, 1996. 46 с.

7. Безопасность деревообрабатывающих станков. Станки круглопильные. Ч. 4. Станки многополотные для продольной резки с ручной загрузкой и/или выгрузкой: СТБ ЕН 1870-4-2006. Введ. 01.01.2007. Минск: Гос. ком. по стандартизации Респ. Беларусь, 2006. 36 с.

8. Гриневич С. А., Гришкевич А. А., Волкович Д. С. К вопросу об обеспечении безопасности при эксплуатации круглопильного оборудования // Труды БГТУ. Сер. 1, Лесное хоз-во, природопользование и перераб. возобновляемых ресурсов. 2020. № 2. С. 325-329. 
9. Волкович Д. С. Расчет импульса и энергии заготовки, выбрасываемой при захвате дисковой пилой: тез. докл. 71-й науч.-техн. конф. учащихся, студентов и магистрантов БГТУ. Минск: БГТУ, 2020. С. $190-191$.

10. Феодосьев В. И. Сопротивление материалов. М.: Гос. изд-во физ.-мат. лит., 1963. 540 с.

11. Писаренко Г. С., Яковлев А. П., Матвеев В. В. Справочник по сопротивлению материалов. Киев: Наук. думка, 1988. 736 с.

12. Маковский Н. В. Проектирование деревообрабатывающих машин. М.: Лесная пром-сть, 1982. 304 с.

\section{References}

1. Grishkevich A. A., Grinevich S. A., Garanin V. N. On the issue of ensuring safety in the operation of circular saw equipment: 84-ya nauchno-tekhnicheskaya konferentsiya, posvyashchennaya 90-letnemu yubileyu BGTU i Dnyu belorusskoynauki (s mezhdunarodnym uchastiem) [The 84th Scientific and technical conference dedicated to the 90th anniversary of BSTU and the Day of Belarusian Science (with international participation)]. Minsk, 2020, pp. 152-153 (In Russian).

2. Volkovich D. S. Determination of the angle of jamming of the toothed curtain: 71-ya nauchno-tekhnicheskaya konferentsiya uchashchitkhsya, studentov i magistrantov BGTU [71st Scientific and Technical Conference of students, undergraduates and undergraduates of BSTU]. Minsk, 2020, pp. 229-231 (In Russian).

3. Ob okhrane truda [On Labor Protection]. Available at: https://pravo.by/upload/docs/op/H11900274 1577394000.pdf (accessed 20.03.2021).

4. Pravila po okhrane truda pri vedenii lesnogo khozyaystva, obrabotke drevesiny i proizvodstve izdeliy iz dereva [Rules for labor protection in forestry, wood processing and production of wood products]. Available at: https://pravo.by/upload/docs/op/W22035383p_1590181200.pdf (accessed 20.03.2021).

5. $O$ bezopasnosti mashin $i$ oborudovaniya [Ōn the safety of machinery and equipment]. Available at: http://www.eurasiancommission.org/ru/act/texnreg/deptexreg/tr/Documents/P 823 1.pdf(accessed 19.03.2021).

6. GOST 12.2.026.0-1993. Oborudovaniye derevoobrabatyvayushcheye. Trebovaniya bezopasnosti $k$ konstruktsii [Woodworking equipment. Safety requirements for the design]. Minsk, Gosudarstvennyy komitet po standartizatsii Respubliki Belarus' Publ., 1996. 46 p. (In Russian).

7. STB EN 1870-4-2006. Bezopasnost' derevoobrabatyvayushchikh stankov. Stanki kruglopil'nyye. Ch. 4. Stanki mnogopolotnyye dlya prodol'noy rezki s ruchnoy zagruzkoy i/ili vygruzkoy [Safety of woodworking machines. Circular sawing machines. Part 4. Multiblade rip sawing machines with manual loading and/or unloading]. Minsk, Gosudarstvennyy komitet po standartizatsii Respubliki Belarus’ Publ., 2006. 36 p. (In Russian).

8. Grinevich S. A., Grishkevich A. A., Volkovich D. S. On the issue of ensuring safety in the operation of circular saw equipment Trudy BGTU [Proceedings of BSTU], issue 1, Forestry. Nature Management. Processing of Renewable Resources. 2020, no. 2, pp. 325-329 (In Russian).

9. Volkovich D. S. Calculation of the pulse and energy of the blank, ejected when gripping a circular saw. 71-ya nauchno-tekhnicheskaya konferentsiya uchashchikhsya, studentov i magistrantov BGTU [71st Scientific and Technical Conference of students, undergraduates and undergraduates of BSTU]. Minsk, 2020, pp. 190-191 (In Russian).

10. Feodos'yev V. I. Soprotivleniye materialov [Resistance of materials]. Moscow, Gosudarstvennoye izdatel'stvo fiziko-matematicheskoy literatury Publ., 1963. 540 p.

11. Pisarenko G. S., Yakovlev A. P., Matveev V. V. Spravochnik po soprotivleniyu materialov [Handbook on the resistance of materials]. Kiev, Naukova dumka Publ., 1988. 736 p.

12. Makovsky N. V. Proyektirovaniye derevoobrabatyvayushchikh mashin [Design of woodworking machines]. Moscow, Lesnaya promyshlennost' Publ., 1982. 304 p.

\section{Информация об авторах}

Гриневич Сергей Анатольевич - кандидат технических наук, доцент, доцент кафедры деревообрабатывающих станков и инструментов. Белорусский государственный технологический университет (220006, г. Минск, ул. Свердлова, 13a, Республика Беларусь). E-mail: grinevich@belstu.by

Гришкевич Александр Александрович - кандидат технических наук, доцент, заведующий кафедрой деревообрабатывающих станков и инструментов. Белорусский государственный технологический университет (220006, г. Минск, ул. Свердлова, 13a, Республика Беларусь). E-mail: dosy@belstu.by

\section{Information about the authors}

Grinevich Sergey Anatol'yevich - PhD (Engineering), Associate Professor, Assistant Professor, the Department of Woodworking Machines and Tools. Belarusian State Technological University (13a, Sverdlova str., 220006, Minsk, Republic of Belarus). E-mail: grinevich@belstu.by

Grishkevich Aleksandr Aleksandrovich - PhD (Engineering), Associate Professor, Head of the Department of Woodworking Machines and Tools. Belarusian State Technological University (13a, Sverdlova str., 220006, Minsk, Republic of Belarus). E-mail: dosy@belstu.by

Поступила 23.03.2021 